October - 2003

\title{
Critical Success Factors in the Infusion of Instructional Technologies for Open Learning in Development Settings: The case of the University of Botswana
}

\author{
Philip M. Uys \\ University of Botswana
}

\begin{abstract}
This article seeks to identify critical success factors for the appropriate infusion of instructional technologies to advance open learning in higher education within developing settings. Describe here is a descriptive account of a two-year case study based on the author's personal analysis of, and reflection on, factors that contributed to the infusion of instructional technologies to advance open learning at the University of Botswana. The first critical success factors identified in this article include: a clear vision, support of committed leadership, and dedicated personnel/ change agents to ensure successful project implementation. The second critical success factor identified was the need for all involved to fully appreciate and understand the systemic nature of the infusion of instructional technologies for open learning purposes, as well as garner the commitment of strategic partners working in related systems. Finally highlighted, are the requirements needed to address the complex nature of the infusion of instructional technologies into the University's educational offerings. It is hoped that those involved in education in developing countries, and particularly those desirous of advancing open learning through the use of instructional technologies, will find this descriptive analysis useful. Indeed, those of us involved in implementing instructional technologies in developing nations are still in the initial stages of this exciting yet challenging endeavour.
\end{abstract}

Keywords: infusion; open learning; instructional technologies; critical success factors; developing settings; development; Botswana; LASO model

\section{Introduction}

This article's aim is to identify critical success factors necessary for the appropriate infusion of instructional technologies into developing settings. It examines the initial stages of a project designed to advance open learning in higher education in Botswana. Currently, there are no theories and models for educational change and development in terms of introducing instructional technology within developing settings. Cannon (1986) further points to the absence of a general theory of educational development. 
Uys $\sim$ Critical Success Factors in The Infusion of Instructional Technologies for Open Learning in Development Settings:

The case of the University of Botswana

Higher education institutes, particularly those operating in developing settings, can therefore benefit by taking cognisance of the 'critical success' factors presented here, for if the infusion of instructional technologies are not systematically and appropriately infused into the educational setting, they can hinder student access, thereby working as an impediment to open learning. Ljosà (1992, p. 91), for instance, asserts "every time we introduce a new technology in a distance education system, we run the risk of introducing a new barrier to participation and learning." Bates (1983, p. 283) points out that ease of access, and thus openness of education, is an important criterion for measuring the success of new technologies in distance education. New instructional technologies can therefore negatively influence equity of access to education as learners, and this is particularly so in developing settings, where learners often find it difficult, if not impossible, to access such technologies. Mason (1999, p. 86) highlights this issue in the European context:

And although the rhetoric about virtual education is that it will extend to the disadvantaged, the remote, the housebound, and the unemployed, those who are signing up for virtual education are the advantaged, the upwardly mobile, the "over-employed" (i.e, those who are already incredibly busy), and the well educated. There is evidence from practitioners that virtual education is more appropriate and more successful for the advantaged learner: one who is motivated, has good learning skills, and has easy access to technology.

This article describes a two-year case study based on the author's personal experience, analysis, and reflection on factors that contributed to the infusion of instructional technologies to advance open learning at the University of Botswana. The insights in this article are based on the author's experiences in spearheading the implementatio phase of new instructional technologies (eLearning) at the University of Botswana. The author served as Deputy Director: Centre for Academic Development (Educational Technology) in the Educational Technology Unit (EduTech, 2003) in the Centre for Academic Development. Since its launch in 2001, the author also led the University of Botswana eLearning (UBel) programme, the purpose of which was to transform teaching and learning at the University through the appropriate use of instructional technologies.

Clearly, those working in developing settings must contend with issues that contrast dramatically with those in developed settings. Many aspects of the socio-economic and technological environment that are taken for granted in developed settings must be explicitly addressed when introducing instructional technologies for open learning in developing settings, such as in Botswana. These include, among other things, participants' unfamiliarity with new instructional technologies, inadequate telecommunications infrastructure, unreliable power supply, competition for limited educational sector resources, and the need to provide basic educational facilities. It is from this viewpoint, that this article analyses elements of the "Leadership, Academic and Student Ownership and Readiness" (LASO) model that guided this extended study. The purpose here is to provide pointers to factors critical to successful infusion of technology to advance open learning in higher education in developing settings.

The factors critical to success identified in this article have emerged from an analysis of the elements of the "LASO Model for Technological Transformation in Tertiary Education" (Uys, 2001a) (see Figure 1) that provided guidance during the first two years of technological implementation at the University of Botswana. The purpose here is to share this experience with other higher education institutions in developing settings. 
Uys $\sim$ Critical Success Factors in The Infusion of Instructional Technologies for Open Learning in Development Settings:

The case of the University of Botswana

UBel was initiated in response to the need for educational reform to mitigate the impact of radical change brought on by growing globalisation and trans-national exchanges in many fields and sectors of society (Marquardt, 1996, p. 3). Scholars such as Evans and Nation (1993) indicated that in "these circumstances politicians, policy-makers, and citizens are making demands upon education systems to reform. Open learning and distance education are at the forefront of educational responses to the changes that are taking place locally, regionally, nationally, and internationally" (p. 7).

The University of Botswana has committed itself to 'open learning' as described by Lewis (1992) as "a conglomeration of educational approaches that aims to transcend the traditional barriers of tertiary education: namely physical, educational, individual and financial barriers” (p. 14). The traditional barriers that Lewis refers to, namely specific locations and times, sequencing of the content and method of delivery, lack of awareness of what is available, and costs of course materials, are also present in higher education in Botswana. The University of Botswana, the nation's only university, has included in its vision statement, 'life-long and open learning approaches' as focal points for the institution. The University further identified student-centred learning as a key component in its vision, which Lewis likewise has identified as a vital feature of open learning.

Open learning at the University has been provided in the past through paper-based distance education and some isolated yet innovative approaches involving face-to-face classroom-based learning. However, in spite of its former reliance on more 'traditional' modes of distance education delivery, e-learning has emerged at the University of Botswana over the last two years as the vehicle through which instructional technologies are being infused to address the above mentioned barriers to education. It is anticipated that the adoption of such technologies will create new avenues for learners to access, open learning opportunities both on and off-campus. The definition of e-learning at the University of being "the appropriate organisation of information and communication technologies for advancing student-oriented, active, open, collaborative and life-long teaching-learning processes," for instance, reflects the University's core goals of providing open learning opportunities, and highlights its commitment to provide e-learning as a means to create such open learning opportunities for Botswana's people.

The technological transformation process at the University has been guided by literature on the infusion of instructional technologies in higher education.

\section{Selected Literature on the Infusion of Instructional Technologies}

Current literature does not provide a neatly formulated theory of generic change or a general theory of educational development (Cannon, 1986). Furthermore, there are no theories or models for educational change and development in the area of instructional technology within developing settings.

Nonetheless, according to Rogers (1995), innovation diffusion theory provides a general explanation for the manner in which new entities and ideas, such as instructional technologies, diffuse through social systems over time. Rogers reviewed studies examining the diffusion of innovations from many technological contexts, and advanced a model for adoption of innovations that described key roles and the desired behaviours that typically occur during the adoption of new innovations. Innovation diffusion theory is essentially a bottom-up approach based on individual responses. The critical importance of visionary leadership during the infusion of 
Uys $\sim$ Critical Success Factors in The Infusion of Instructional Technologies for Open Learning in Development Settings:

The case of the University of Botswana

instructional technologies at the University of Botswana correlates with a central finding of the author's doctorate research (Uys, 2000) that show that when the innovation emerges from outside of senior management, Rogers' diffusion of innovation theory needs to be augmented with a topdown component that includes the support of both senior and middle management in order to accomplish the effective diffusion of instructional technologies within a given higher educational setting.

Szabo, Anderson, and Fuchs (1997) developed a change model called the Training, Infrastructure and Empowerment System (TIES) for implementing alternative delivery systems at the University of Alberta in Canada. The TIES model suggests the following five phases for infusion alternative delivery systems: vision building, identification of departments, development of ties workshop and modules, TIES Leadership Task Force (TLTF), training and follow up support. The TIES model, however, does not provide a strategic framework to guide the implementation of instructional technologies in an institution of higher education.

Bates (2000) highlights the importance of leadership in the technological change process by asserting "...the widespread use of new technologies in an organization does constitute a major cultural change. Furthermore, for such change to be successful, leadership of the highest quality is required" (p. 42).

At the University of Botswana, the LASO Model for Technological Transformation in Tertiary Education (Uys, 2001a) (see Figure 1) was selected to guide the implementation and selection of appropriate strategies.

Figure 1. The Leadership, Academic and Student Ownership and Readiness (LASO) Model for Technological Transformation in Tertiary Education

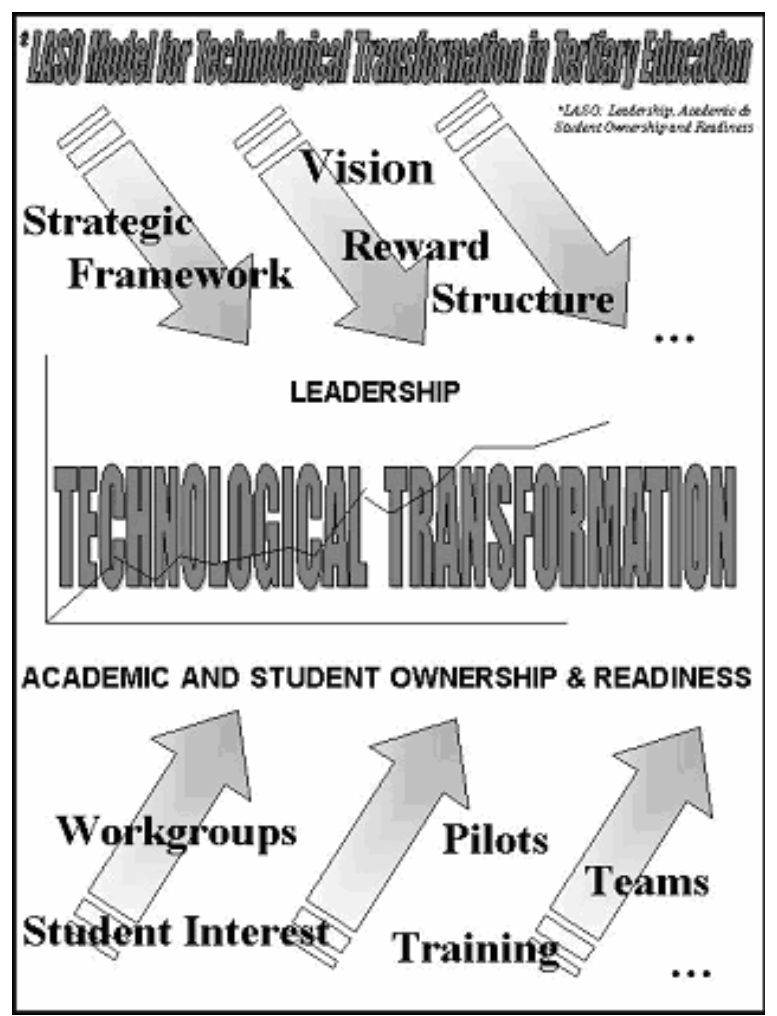


Uys Critical Success Factors in The Infusion of Instructional Technologies for Open Learning in Development Settings:

The case of the University of Botswana

Based on the implementation of instructional technologies in higher education both in developed and developing settings, the LASO model emphasises the importance of integrated top-down and bottom-up processes, as was proposed by Gunn (1998) and suggests that effective technological infusion occurs when leadership is matched with corresponding academic staff and learner ownership and readiness. Leadership is achieved through mechanisms such as defining a clear vision for the infusion, providing a reward structure for those engaging in the change process, and the creation of a strategic framework to guide the infusion process.

The LASO model suggests that ownership and readiness for change on the part of learners and academic staff, can be achieved by using strategies such as pilot projects, extensive training, establishment of workgroups and learning communities in every faculty, and use of teams for elearning courseware development. The curve of technological infusion is indicated in the LASO model as a ragged line used to signify the complexities and dilemmas with which the infusion of instructional technologies in higher education is often associated. The LASO model also describes an integrated view of the systemic nature of the infusion of instructional technologies.

In sum, this article attempts to identify the critical elements of the LASO model that led to the increased use of instructional technologies for advancing open learning at the University of Botswana.

\section{Instructional Technologies for Advancing Open Learning at the University of Botswana}

Technological transformation is supporting increased student access to open learning opportunities at the University of Botswana. Overhead projectors, for example, were first introduced on a large scale in 2000. Yet two years later, the University of Botswana now finds itself using an online learning content management system whereby courses are offered via WebCT within various cutting-edge facilities and systems. Online learning has made open learning a reality for learners in many of the faculties and departments at the University. More than 4,000 learners, enrolled in over 70 courses, are currently conducting a portion of their learning activities online.

While conventional paper-based distance education is still widely used in the University's Centre for Continuing Education, in 2003 two pilot studies were identified to introduce newer instructional technologies. Such pilots support the Centre for Continuing Education's open learning activities.

A state-of-the-art e-Learning Support Centre (see Figure 1) has been implemented as the first wireless network application at the University of Botswana. Computers, which are laid out in clusters to support collaborative work, are placed so as to facilitate eye contact among group participants. A Mimio-board is used to display, via a data-projector, what is written or drawn on the white-board. Microsoft-NetMeeting is used to project the white-board or any other aspect of the instructor's screen on the screens of all the participants, or the screen of any participant to all other participants.

The eLearning Support Centre, which held more than 60 workshops, has been used to train more than 30 percent of the UB 720 member academic community in various educational technologies. A new 'eLearning Certificate,' issued by the Centre for Academic Development, has been designed by EduTech and is being offered since the beginning of 2003. 
Uys $\sim$ Critical Success Factors in The Infusion of Instructional Technologies for Open Learning in Development Settings:

The case of the University of Botswana

After rigorous evaluation, in 2002, the University acquired WebCT, an online learning management system. More than 70 courses are currently online, providing approximately 4,000 (of the 12,000) learners with open learning opportunities. WebCT offers a full suite of online learning tools including chat facilities, bulletin boards, online calendar, assessment tools, learner tracking, email, content uploading, and learner administration.

In 2003, a video-conferencing system, POLYCOM, was installed for synchronous teaching and learning, linking the main campus in Gaborone with Maun and Francistown via ISDN and leased lines. The University of Botswana can also conduct video-conferencing internationally through this system using IP addressing or ISDN.

The Internet and particularly the Web is playing an increasingly important role as e-learning expands. Learner use of the Web has increased exponentially; so has the demand for more computers and faster access.

EduTech has a central equipment outlet and has seen a dramatic increase in the demand and use of laptops and mobile data projectors by academic staff. A satellite model is being implemented whereby each faculty will have its own educational technology and e-learning centre (eCentre) to provide customised support, instructional design, training, and equipment services.

Implementation of a computerised system for issuing equipment using a bar-code system at the central educational technology outlet is now at an advanced stage. In the future, academic staff will be able to both check availability and reserve equipment online.

An e-learning Smart Classroom has been co-designed with visiting consultants (Brown and Peterson, 2001) and constructed for technology-based, open, active, and collaborative learning. This classroom is laid out in a similar fashion to the eLearning Support Centre with clusters of computers situated in such a way as to provide eye contact. The Smart Classroom also features a video-conferencing system and a number of motorized screens for maximum flexibility in sharing information.

This article has focused on analysing the elements of the LASO model to determine which elements have been critical to the increased use of instructional technologies for advancing open learning at the University of Botswana.

\section{Critical Success Factors for the Infusion of Instructional Technologies for Open Learning in Developing Settings}

Although various factors and elements both within and external to of the LASO model contributed to the increased use of instructional technologies for open learning at the University, the following elements have emerged as the critical success factors in the initial stages the transformation process:

- Vision, leadership, and dedication

- Appreciation for the systemic nature of the infusion of instructional technologies for open learning and a commitment to work with strategic partners in related systems

- Address the complex nature of the infusion of instructional technologies 
Uys Critical Success Factors in The Infusion of Instructional Technologies for Open Learning in Development Settings:

The case of the University of Botswana

A strategic framework is indicated as important in the LASO model; however, current progress at the University of Botswana has been made in the absence of clear strategic plans and policies. It is envisaged that such a strategic framework will become critical in the future systematic rollout of instructional technologies for open learning.

A top-down strategy of the LASO model ensures that adequate rewards systems exist. Experiences at the University has supported this notion, but most progress in the technological transformation thus far has taken place without monetary rewards or time-release.

One of the bottom-up strategies in the LASO model is the stimulation of student interest. At the University this strategy has not been used to any significant degree thus far, because student access to networked computers has become a major bottleneck, hindering further implementation of instructional technologies for open learning at this time.

\section{Vision, Leadership and Dedication}

An inspiring vision for the use of new instructional technologies for open learning has proved to be critical at the University of Botswana, providing direction and inspiration to the pioneers both within the academic and support dimensions of the University.

At the University of Botswana, the work of the UBel programme links to Botswana's Vision 2016 (Presidential Task Group, 1997) goals of being an educated, productive, innovative, and informed nation as it aims to provide wider and open access while increasing the quality and relevance of tertiary education in an emerging global information society.

The vision of the University of Botswana to transform its academic processes towards an increasingly technological base has strongly influenced the strategic implementation of instructional technologies at the University. The stated vision of the University is to strive for increasing access, thereby opening up tertiary education to meet Botswana's national aims of increasing excellence in the provision of education to the nation, and in particular to use ICTs in the teaching and learning process.

The Educational Technology Unit (EduTech) that is spearheading the UBel programme has as its purpose "to spearhead the appropriate and innovative integration of educational technologies in teaching and learning processes, and to provide a technologically advanced and relevant learning environment." This vision is progressively being realised to create open learning opportunities for the more than 12,500 learners at the University.

Vision without leadership, however, is at best a fantasy, and at worse a farce. Strong leadership for the use of e-learning, however, has been provided on various levels at the University of Botswana and confirms the view of Berge and Schrum (1998) that the support of campus leaders is key to successful campus initiatives (i.e., in technology-enhanced learning and distance education). This further correlates with Drucker's (1985) assertion that a successful innovation should aim from the outset at leadership in order to be innovative enough and capable of establishing itself.

In this regard, the writer has provided direct leadership through EduTech, as champion of the use of new instructional technologies at the University of Botswana and as chair of the UBel Committee. The respective faculty representatives on the UBel Committee have further provided 
Uys $\sim$ Critical Success Factors in The Infusion of Instructional Technologies for Open Learning in Development Settings:

The case of the University of Botswana

leadership within their respective faculties. Dedication and committed work from within EduTech, the UBel Committee and pioneers among the academic staff are making a reality the University's vision for advancing open learning through the use of instructional technologies.

\section{Appreciation for the Systemic Nature of the Infusion of Instructional Technologies for Open Learning and a Commitment to Work with Strategic Partners in Related Systems}

Technological innovation has often been implemented as an isolated, bottom-up initiative of academic staff for efficiency or experimental purposes. In this scenario, the wider systems within tertiary education are often not considered nor affected by the innovation, which has led to isolated opportunities for open learning. Without being consulted first, senior management often may thus feel justified in disregarding the innovation.

Solely top-down attempts have likewise met with failure when the systemic nature of change and, in particular, academic involvement and ownership were not valued as critical prerequisites to sustainable technological infusion. Tillema (1995) points out that historical studies, based largely on experience in schools, show that top down efforts to achieve educational reform have failed, and suggests that they will be doomed to continued failure until they deal with the cultural and pedagogical traditions and beliefs underlying current practices and organizational arrangements.

Attempts to introduce any significant reform in an institution towards open learning will impact on most of its sub-systems. Bates (2000), for instance, contends, “...using technology to extend the campus on a global basis will affect all aspects of a university or college, but particularly administrative systems." Systems theory in general (Bertalanffy, 1968) also calls for an integrated approach to technological innovation, since a system is defined as a whole that cannot be effectively studied without studying all its part as well as the whole.

Technological change at the University of Botswana to advance open learning has confirmed the need for systemic considerations. EduTech considers integrative approaches with adjoining systems and sub-systems as imperative and is therefore partnering with such units as the Information Technology Department, the Library, and the Centre for Continuing Education, and of critical importance, with academic staff. The Information Technology Department has an important role in providing a stable, sustainable, and appropriate technological infrastructure. The Library needs to provide an increasing number of accessible electronic resources. The Centre for Continuing Education (CCE) is committed to integrating Web-based learning into their largely paper-based distance education systems. CCE will also be the main users of the videoconferencing systems. Additionally, central access to networked computers must increase from the current 200 computers to 800 in the next three years.

A sub-system currently out-of-phase in the implementation of instructional technologies at the University, is the provision of adequate access to networked computers for learners. Academic staff regularly report that students complain of their inability to obtain access to digital materials. A study is underway to determine the exact nature of the problem and to determine possible strategies to overcome this major hurdle.

Academics are deeply involved in the reform process through the UBel Committee and the eTeams that have been established in each Faculty. Two academic staff members on the UBel Committee represent each Faculty, and these staff members, as members of an eTeam, lead the 
Uys $\sim$ Critical Success Factors in The Infusion of Instructional Technologies for Open Learning in Development Settings:

The case of the University of Botswana

eLearning programme within their respective faculties. Through the UBel Committee, academic staff members selected the online Learning Management System. They also conducted a University-wide needs analysis and contributed to the design of the 2003 eLearning pilot programme.

The University of Botswana experience concurs with the view of Tillema (1995) who stated that engaging academics in the reform process is one of the significant management issues to address not only in educational reform, but also in education in general. It therefore seems essential to address the concerns and perceptions of academic staff in view of the need for changed attitudes and ownership by academic staff, towards the infusion of instructional technologies for open learning in higher education.

The training programme at the University of Botswana has been vital in preparing academics for this new role. Involvement in training has lead to ownership of the infusion of instructional technologies by academics. As pointed out above, EduTech has conducted more than 60 instructional technologies workshops since February 2001, attended by more than 30 percent of the 720 member academic staff at the University.

\section{Addressing the Complex Nature of the Infusion of Instructional Technologies}

The implementation of instructional technologies for open learning is a complex process. Morrison (1995) describes this process in terms of dislocations, dilemmas, and uncertainties, rather than progression from 'what is' to 'what is needed.' The process at the University has proved to be complex due to its systemic dimensions and because people are central to the transformation process (Uys, 2000; Uys 2001b; 2002; Uys, Nleya and Molelu, 2003).

The ragged contour of technological infusion as depicted in the LASO model above has also been confirmed at the University of Botswana in contrast to the smooth contours of Roger's (1995) diffusion of innovation curve. These observations correlate with the writer's findings based on a three-and-a-half year doctoral study of infusing e-learning in a developed setting at Massey University in New Zealand (Uys, 2000).

Difficulties in human relationships, lack of resources at critical stages, bureaucratic interference, change fatigue, and dealing with diverse expectations, all contributes to the complexity of implementing and using instructional technologies for open learning at the University of Botswana. Other complexities evident within the transformation process at the University include managing the relationships among UBel Committee members, providing access for learners to computers, instability of information and communication systems, lack of learner participation, resistance to change among academic staff, and extensive time delays due to administrative processes and procedures. There is also a tremendous need for basic computer literacy among both learners and academic staff.

The role of the teacher in open learning is changing (Collis, 1998). There is an emerging certainty that the role of teacher will become more that of facilitator rather than sole providers of information (Hodgson, Mann, and Snell, 1987; Mason, 1998). Academic staff members, however, exhibit strong resistance to changes in traditional beliefs and practices (Taylor, Lopez, and Quadrelli, 1996). 
Uys Critical Success Factors in The Infusion of Instructional Technologies for Open Learning in Development Settings:

The case of the University of Botswana

Learners are likewise required to assume new roles and responsibilities in the University that contrast sharply to the predominant teacher-centric delivery approaches that learners were accustomed to in secondary school. Online learning, for instance, encourages what Hodgson, Mann and Snell (1987), perceive the use of "...new technology as a vehicle for the sharing of discoveries, developments, and reference materials among an expert network of peer specialists” (p, 165). According to Mason (1998), new technologies in global education leads to information being “...no longer something to organise, transmit and memorise, but something to work with, think with, discuss, negotiate and debate with partners” (p. 157).

\section{Summary and Conclusions}

The problem that this article sought to address is whether critical success factors can be identified for the appropriate infusion of instructional technologies in the initial stages to advance open learning in higher education within developing settings.

Based on the personal analysis and reflections of the writer, this article employed a descriptive account of a two-year long case study. A more collaborative approach to the analyses could, however, have provided further insights on the infusion of instructional technologies to advance open learning at the University of Botswana.

The study has led to the identification and description of three factors that have emerged thus far as critical to successful technological transformation. The first factor consists of the need for clear vision, committed leadership, and dedicated change agents. The second factor is the need for appreciation of the systemic nature of the infusion of instructional technologies for open learning and a commitment to work with strategic partners in related systems. The third factor is the need to address the complex nature of the infusion of instructional technologies.

The multi-faceted complexities and challenges that militate against effective diffusion and adoption of instructional technologies, particularly in developing settings, necessitate contextualisation of infusion models and processes that might have proven to be effective in developed settings.

In conclusion, the author's objective in writing this article has been to share his analysis and reflection on a two year project of infusion of educational technologies at the University of Botswana with others interested in, or working in, developing settings. While developed nations have already addressed such challenges in regards to infusion technology into educational environments, for those working in higher education in developing countries, such as Botswana, this is very new and exciting territory indeed.

\section{References}

Bates, A. W. (2000). Managing Technological Change: Strategies for college and university leaders. San Francisco: Jossey-Bass.

Bates, A. W. (1983). Trends in the use of audio-visual media in distance education. In D. Sewart, D. Keegan, and B. Holmberg (Eds.) Distance education: international perspectives. London: Croom Helm. 
Uys Critical Success Factors in The Infusion of Instructional Technologies for Open Learning in Development Settings: The case of the University of Botswana

Berge, Z. L., and Schrum, L. (1998). Strategic planning linked with program implementation for distance education. CAUSE/ EFFECT, 21(3), 31 - 38.

Bertalanffy, L. Von (1968). General Systems Theory: Foundations, development, applications. New York: George Braziller.

Brown G., and Peterson, N. (2001). eLearning, The Library Learning Centre: Spaces \& strategies. Report to the University of Botswana.

Cannon, R. A. (1986). Theoretical perspectives in changing tertiary education. In J. Jones and M. Horsburgh (Eds.) Research and development in higher education. Kensington, Australia: HERDSA.

Collis, B. (1998). New wine and old bottles? Retrieved July 13, 2003, from: http://utocp189.oc.utwente.nl/oc/dies/diesredescollis.htm

Drucker, P. F. (1985). Innovation and Entrepreneurship. London: Heinemann.

Evans, T., and Nation, D. (1993). Reforming Open and Distance Education: Critical reflections. London: Kogan Page.

EduTech (2003). Educational Technology Unit, 2003. Retrieved July 25, 2003, from: www.ub.bw/departments/centres/cad_et.html

Gunn, C. (1998). Virtual Technologies in Higher Education: Vision or reality?. In M. Peters and P. Roberts (Eds.) Virtual technologies and tertiary education. London: Routledge.

Hodgson, V. E., Mann, S. J, and Snell, R. (1987). Beyond Distance Teaching - Towards Open Learning. Milton Keynes: Open University Press.

Lewis, R. (1992). What is open learning? In A. Tait (Ed.) Key issues in open learning. (p. 11-23). Harlow, UK.: Longman.

Ljosà, E. (1992). Distance education in a modern society. In A. Tait (Ed.) Key issues in open learning. Harlow, UK.: Longman.

Mason, R. (1998). Globalising education. Trends and applications. London: Routledge.

Mason, R. (1999). European trends in the virtual delivery of education. In G. M. Farrell (Ed.) The development of virtual education: a global perspective. Vancouver, BC.: The Commonwealth of Learning.

Marquard, M.J. (1996). Building the learning organization - a systems approach to quantum improvement and global success. New York: McGraw-Hill.

Morrison, T.R. (1995). Global transformation and the search for a new educational design. International Journal of Lifelong Education 14(3), 188 - 213. 
Presidential Task Group (September 1997). Long Term Vision for Botswana - Vision 2016.

Rogers, E. (1995). Diffusion of Innovations. 4th edition. New York: Free Press.

Szabo, M., Anderson, T., and Fuchs, A. (1997). A change system: the training, infrastructure and empowerment system: (TIES). Retrieved July 10, 2003, from: www.quasar.ualberta.ca/edmedia/TIES/TIES Report.html

Taylor, P., Lopez, L., and Quadrelli, C. (1996). Flexibility, Technology and Academics’ Practices: Tantalising tales and muddy maps. Evaluations and Investigations Programme, Department of Employment, Education, Training and Youth Affairs, Canberra. Retrieved June 20, 1998 from: http://www.anu.edu.au/uniserve/eip/muddy/muddy.html

Tillema, H. H. (1995). Changing the Professional Knowledge and Beliefs of Teachers: A training study. Learning and Instruction, 5, 291 - 318.

Uys, P. M., Nleya, P. N., and Molelu, G. B. (2003). Technological Innovation and Management Strategies for Higher Education in Africa: Harmonizing Reality and Idealism. Educational Media International, 40(3/4). London: Rouledge.

Uys, P. M. (2002). Networked Educational Management: Transforming Educational Management in a Networked Institute. Campus Wide Information Systems (CWIS),19(5), 175 - 181.

Uys, P. M. (2001a). LASO (Leadership, Academic \& Student Ownership and Readiness) Model for Technological Transformation in Tertiary Education. Retrieved September 1, 2003, from: www.globe-online.com/philip.Uys/LASOmodel.htm

Uys, P. M. (2001b). Managing Tertiary Education in a Global Virtual Environment: Networked Educational Management. In R. Hazemi, S. Hailes, and S. Wilbur (Eds.) The Digital University: Building a Learner Community. London: Springer-Verlag.

Uys, P. M. (2000). Towards the Virtual Class: Key management issues in tertiary education. Unpublished PhD thesis. Victoria University of Wellington, New Zealand.

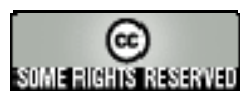

